(REVIEW ARTICLE)

\title{
Risk management in construction sector
}

\author{
Oğuzhan Yavuz Bayraktar* \\ Kastamonu University, Faculty of Engineering and Architecture, Department of Civil Engineering, Kastamonu.
}

Publication history: Received on 15 November 2020; revised on 24 November 2020; accepted on 25 November 2020

Article DOI: https://doi.org/10.30574/wjarr.2020.8.2.0433

\begin{abstract}
The major requirement of every construction project is meeting client's need of cost, quality and time. However, the construction industry is overwhelmed with risks more than any other industry due to the fact that they are present in every activity from design to completion. These risks need to be controlled early or face the possibility of cost overruns, time delays and poor quality work leading to displeasure of client and public. Although risk management in construction projects is a very important issue in terms of the firms operating in the construction sector, it has not yet gained clarity and prevalence in our country. Within the scope of this research, the aim of this research is to introduce the risk management system as a concept and to classify the risk in construction projects and to demonstrate the risk management techniques. Risk management system is a cyclic process. In the monitoring and control phase of applied risk responding strategies, some of the risks will be eliminated or reduced, some of unforeseen risks will appear and analysis steps will be realized again. At the end of the project, determination of to what degree project aims and targets have been reached and documentation of risk management system after evaluation regarding to the project will enable the company to use project risk management system more effectively and usefully in the projects undertaken later. Due to construction activities, processes, environment and organization's structures, construction industry and the clients are broadly in relation with high risk degrees. Therefore, it is highly important for our country's firms in construction industry to give necessary significance to project risk management idea and system and to consider them as a basic function of the projects for permanence of their enterprise existence.
\end{abstract}

Keywords: Construction Activities; Construction Sector; Risk Management

\section{Introduction}

Risk management is a project management technique that includes identifying the risks in a project, determining the impacts on the project, and determining the measures that can be taken after the necessary arrangements are made, taking into account the uncertainties. Risk management, which can be defined as an approach in which the balance between the project and the risks involved in the project is determined and that the balance is intended to deteriorate the yields with the implementation of the right strategies, includes the features that can provide many advantages for the construction sector, which is the locomotive of the economy in developing countries [1]. In construction sector; Depending on the extent of the project, its intricacy, the strategies utilized and the earth in which it is completed, it is conceivable to limit the monetary misfortunes and question that may emerge between the gatherings by efficiently assessing the risks that might be available at various rates in each project. Be that as it may, the techniques utilized in the project assessment arrange frequently don't permit a reasonable examination of the risks. The most noteworthy distinction between risk management and different techniques is that it is precise [2].

The most broad meaning of risk management; This comprises of characterizing and ordering the risks, deciding the sizes and settling on proper choices relying upon the frames of mind of individuals about the risk. The principle motivation behind the risk management rehearses isn't constrained to guaranteeing the end of risks in opposition to

\footnotetext{
* Corresponding author: Oğuzhan Yavuz BAYRAKTAR

Kastamonu University, Faculty of Engineering and Architecture, Department of Civil Engineering, Kastamonu.
} 
the present general assessment, deciding the impacts of the risks on the project, reestablishing the forward-looking conjectures on a progressively strong premise, mirroring the risk factor to the guidelines amid the assessment stage and deciding the suitable terms of agreement and the risks that the gatherings accept. Further consideration [3].

\section{Risk Management}

All together for any project to be viewed as achievable by the business, a few criteria are resolved, for example, the expense is not exactly a specific number and the construction is finished before a specific date. In this manner, by the commitment of the contractual worker to play out the project, a portion of the risks that will influence the acknowledgment of these criteria are embraced by the temporary worker. The temporary worker, in concurrence with the subcontractors, exchanges a portion of the risks that he attempts to these people/associations. Amid this procedure, sharing of risks is guaranteed through contracts [4].

It is unavoidable that the side that overlooks the impacts of the risks and which does not set up the important prudent bundles in a troublesome circumstance if the risks are figured it out. The temporary worker does not need to make any further game plans if the protection is made for the real risk factors, for example, catastrophic events however farfetched to happen. Notwithstanding, if there is a risk that the cost increments will be embraced by the temporary worker, as in single amount projects, the fundamental game plans ought to be made at the delicate stage [5]. Thinking about these issues, all gatherings engaged with the acknowledgment of such a project, by making a risk management framework, limit future debate and monetary misfortunes. A risk management framework that has been set up in the beginning periods of the project and refreshed amid the entire project is a project management system that can decidedly influence the accomplishment of the project, particularly in enormous projects [6].

\subsection{Risk Management System}

Albeit distinctive methodologies have been proposed by the diverse specialists for the Risk Management System, this idea is fundamentally; distinguishing proof and investigation of risks, and assessment and basic leadership forms. CRMS (Construction Risk Management System); While recognizing risks, including risk examination and assessment, arrangement advancement and framework management steps [7], SCERT (Synergistic Contingency Evaluation and Response Techniques), which is created for the arranging and monetary assessment of substantial projects. In the model, there are organizes in which the risks for exercises and each movement are characterized, arrangements are delivered for each risk, optional risks made by the created arrangements are recognized, new arrangements are proposed, probabilities are resolved and the outcomes are assessed with probabilities [9].

The assurance of every single unsure factor that may influence the result of the project is the most essential period of the risk management framework. In this way, a characterized risk is never again a risk however turns into a management issue [10]. Wrong or inadequate risk recognizable proof may cause the risk management framework to crumple. The proposed technique to use at this stage is to set up a Risk Identification Group comprising of experienced and innovative people who will participate in different phases of the project and to set up a Checklist that incorporates the risks that may influence the accomplishment of the project. The Checklists are principally founded on the learning of the gathering individuals, the records of the old projects, the data acquired through conference with the specialists, measurable information, the consequences of the review to be readied and the agendas arranged for the recently acknowledged projects [11].

The most reprimanded point at this stage is the way that, because of the absence of measurable information in the construction projects, the choices ought to be given based on the abstract information and there is no proposal of an efficient strategy. Despite the fact that the utilization of agendas arranged for past projects has turned into the most deliberate methodology, the low likelihood of event of two indistinguishable projects because of the dynamic idea of the construction projects has been reprimanded for the way that the old agendas could contain pointless risk factors and cause superfluous risks in the new project to go amiss from the objective [12].

Among other suggested deliberate methodologies, "Monetary Document Method" and "Stream Chart Approach" are considered as deficient strategies for construction projects [8]. For this situation, the sufficiency of the Supremacy of control stays constrained to the individual perception, experience and judgment of the gathering individuals. Another examination that might be helpful in this stage is to look at the occasion impact relationship for each risk component in the agenda. If there should arise an occurrence of acknowledgment of the risks, the conceivable results, for example, work misfortune, physical harm and money related misfortunes can be resolved and the risks are arranged by the potential impacts and the risks to be considered in the examination stage can be resolved [13]. Moreover, since there 
might be a few risks that are not predicted in the execution of the project, the Checklists ought to be refreshed every once in a while and ought to be free from the risks that have been lost [8].

\subsection{Classification of Risks}

One of the most important issues to be addressed in the construction sector is the growing population and the creation of new residential areas from rural to urban areas. This makes the construction of new buildings mandatory. This process increases the density of people and therefore buildings in the unit area. In order to meet the housing needs of people, the establishment of new living spaces and therefore the construction of new buildings lead to the disclosure of the risks that may arise from the project and the risks should be classified [27,28,29,30,31].

Amid the characterization of risks, the risks in the updated agenda ought to be arranged by their controllability, probability of event and the size of their effect. This gives a relative comfort to the examination stage. A few specialists want to decrease this investigation into a solitary stage by consolidating it into the ID of risks [14].

\subsubsection{Risk analysis}

Risk investigation is the way toward deciding the impacts of characterized risks on the project. The basic purpose of numerous systems that are prescribed to be utilized at this stage is to analyze every single imaginable outcome by considering every one of the qualities that the vulnerability parameters can go out on a limb [15]. In the construction sector, the conventional technique used to mirror the impacts of risks on the project is constrained to the expansion of a specific rate to the expense as a risk resistance in the wake of ascertaining the project costs. It is commonly expected that the risk resilience, which is resolved as roughly 10 percent of the cost, disposes of the conceivable money related misfortunes of the temporary worker. Notwithstanding the size and changeability of risks, the utilization of a similar face for each project isn't a suitable and sensible technique. The inadequacies that can be recognized with this strategy can be outlined as pursues [16];

- People's encounters are used in choosing fitting risk resilience. In any case; the utilization of these qualities for new and beforehand hidden construction projects will permit deluding results.

- The outcome acquired by adding a specific fixed rate to the expense ought not be relied upon to mirror all suppositions since it can't be recouped from being a monovalent methodology.

- The expansion of risk resistances to the expense reflects just the likelihood of the negative event. For this situation, the likelihood of a dubious occasion to be decidedly ignored is neglected [17].

- The utilization of this strategy can prompt the threat that in an extremely unsafe manner individuals take out the risks. Since an itemized risk distinguishing proof eliminate is regularly not conveyed, there is a high probability of missing risks. Subsequently, this customary strategy ought not be considered as an option in contrast to the risk management framework.

The essential advantage of risk examination procedures is that the perspectives on the impacts of risks on the project can be reflected in forward-looking gauges and the emphasis is on numerous conceivable results instead of monovalent methodologies. There are numerous hypothetical and numerical procedures proposed for this reason. Nonetheless, in spite of what is trusted, risk investigation does exclude methods that require a ton of numerical aptitudes and require just numerical examination. What is critical amid the examination is the way that reasonable forecasts are made and the consequences of vulnerability are translated effectively. That thoughts can be communicated solidly [18].

The sorts of projects where risk examination is especially fundamental can be recorded as pursues [19]:

- Macro-financial projects requiring huge scale venture,

- Projects in which unequal and sporadic income explanations are in power,

- Large projects in which new advancements will be attempted,

- Projects in which whimsical legitimate courses of action and contract types are substantial,

- Projects acknowledged in situations delicate to questionable monetary and political parameters, 
- Projects where severe principles are established, particularly natural insurance and safety efforts.

\subsubsection{Evaluation and decision making}

The last phase of the risk management framework incorporates the assessment of the aftereffects of the investigation dependent on the demeanors of the chiefs on risk and contemplating the risk impacts. The answers for be delivered and the choices to be made at this stage are firmly identified with the frames of mind of the experts on risk and are principally founded on two methodologies, for example, risk control and risk financing [10]. Risk control can be abridged as the methodology of controllable risks by playing it safe and diminishing the consequences for the project. Be that as it may, it is beyond the realm of imagination to expect to control all risks. Risk financing is the way to deal with take important measures and take estimates considering the conceivable money related misfortunes that may happen on the off chance that risks happen. Guidelines, for example, reexamining the terms of the agreement or including the risk factor at a specific rate of offer esteem are translated inside the extent of risk financing. Accordingly, experts have not overlooked the risk impacts by utilizing distinctive methodologies at the basic leadership organize and know about the conceivable outcomes. The picked technique is to dismiss the project and not offer if the risks are too enormous to be embraced; in different cases, it might appear as exchanging the risks to different people/associations, taking out protection, disposing of risks with proper measures or undertaking all risks [20].

As effectively stressed, deciding the sort and states of the agreement is a standout amongst the most vital components of the risk management framework. Be that as it may, the customary kinds of agreements keep the formation of a sensible risk management framework. In a framework dependent on the guideline of choosing a low-valued proposition, the gathering who risks the risks in a practical evaluation condition is at risk of not landing the position this time. For this situation, the proposed arrangement is that the business recognizes the risks in vast projects and the temporary workers request data on the best way to go out on a limb in their offers. With this technique, future question can be counteracted. It was discovered that by choosing the proper sort of agreement, it is conceivable to set aside to $5 \%$ in project costs [4]. In this structure, it is endeavored to grow new sorts of agreements went for methodicallly covering the risks for the present high-risk projects [21].

\section{Risk Management Techniques}

Project risk management is a control that includes understanding the project to achieve a few benefits. In this order, there is far reaching data about the apparatuses and strategies expected to make project risk computations.

Loosemore (2012) have created different risk examination methods to be utilized in construction projects. These methods incorporate risk premium, risk-balanced rebate rate, abstract likelihood, choice investigation, affectability examination, Monte Carlo reproduction, stochastic predominance, instinct and Caspar [22]. One approach to control risks in construction projects is to create solid project conjectures and plans. Distinctive strategies, for example, PERT (Program Evaluation And Review Technique), PNET (Probability Network Evaluation Technique), NRB (Narrow Reliability Bounds) and Monte Carlo Simulation (MCS) are utilized to quantify the arranging risks of the projects and to gauge changes in movement periods.

Procedures (Algorithms), end-end investigation, Bayesian Theory and choice tree basic leadership examination strategies. These techniques give basic leadership devices in vulnerability conditions. A Process way (calculation) contains a succession of directions for taking care of issues. Mean end examination is a strategy for elucidating a lot of focuses for deciding a progression of choice focuses. The choice tree indicates known determinations (Alternatives) and their conceivable yields over a tree structure. In this manner, the chief can decide the best answers for achieve the objective in the fundamental project. The choice tree strategy is valuable in settling on choices between construction techniques, picking between various projects, regardless of whether the exchange requires pay, and the issue identified with the agreement, for example, deciding the probability of a given pay [23].

Monte Carlo investigation is a (stochastic) type of reenactment utilizing arbitrary factors. Utilizing this technique, the likelihood of project yields is acquired through various emphasess relying upon the ideal level of unwavering quality. Caspar is the recreation with the assistance of a PC for project estimation and survey. It is a project management apparatus that structures redundancy time, assets, expenses and incomes all through the whole project process. Assess the aftereffects of components, for example, deferral and expansion. Such PC based techniques consider the dynamic project condition. The utilization of conventional strategies to decide a restricting way is scrutinized by the inability to consider the consecutive idea of the construction management process. In the analyst's view, the sensible risk model should cover project vulnerability as a dynamic procedure. Therefore, the chief may change the arrangement relying upon the project procedure. Hence, in cutting edge models and procedures, the scientist is bound by vulnerability with 
WBS. The abstract probability depends on the experience picked up by the leader in comparative projects before, where the basic leadership is formed by risk and the choice relies upon the risk presentation and the risk yields. They take expanded breaking points to cover and gauge risk esteems, risk designs or unanticipated probabilities in construction projects. The changing qualities between the projects by and large rely upon the risks and the risk circumstances that are compelling to choose [24]. By taking a gander at the looks into made up until this point, we can say that each part should make its own risk appraisal in the project. For instance, as indicated by the structure proprietor, the rundown of huge risks is totally extraordinary to the temporary worker. Likewise, while the proprietor of the construction needs to take a gander at large scale resemblance, the temporary worker needs to analyze the conceivable outcomes of progress in more detail. The landowner manages more project expenses and work projects to anticipate project financing. Then again, the temporary worker needs to add to the proposition the effect of littler risk territories and vulnerabilities on project cost and time, as a coherent vulnerability, particularly in focused turnkey projects. It is essential to deliberately assess these vulnerabilities [25,26].

\section{Conclusion}

The way that risk management has a critical spot in project management originates from the natural risks inalienable in the projects. Each project is one of a kind, one-off, and unique. Along these lines, it is conceivable to confront unanticipated risks just as unsurprising risks. A risk can be for at least one reasons and can have various impacts when it happens. Since each project is extraordinary, risk management is required in projects. The projects are mind boggling at each stage since they contain numerous exercises and convey risks based on movement. As no project is indistinguishable, it is likewise conceivable to make changes and modifications in the project procedure. So as to end the project with the arranged spending plan at the planned time, corrections and exercises can be changed.

Suppositions, requirements, commitments and work power can prompt risk in the project procedure. So as to accomplish the ideal objective of the project to be finished effectively, these risks ought to be foreseen and convenient averted. These risks will be recognized and averted before they happen or their effect on the project will be diminished through risk management. The wellspring of the project risk is the vulnerabilities in the projects. The realized risks are the risks that can be distinguished and broke down. Plans ought to be made for these risks in accordance with risk management forms. Such estimates are unrealistic for obscure risks. The crisis intends to be made by the project group will limit the impacts of obscure risks on the project and limit the harm. Recognizing openings and dangers in the project is of extraordinary significance in projects. Risks can be accepted if there is a harmony among circumstances and dangers.

\section{Compliance with ethical standards}

\section{Acknowledgments}

I would like to thank anonymous reviewers for constructive comments on the manuscript.

\section{Disclosure of conflict of interest}

The author declare no conflict of interest.

\section{References}

[1] Shen, L. Y., Platten, A., \& Deng, X. P. Role of public private partnerships to manage risks in public sector projects in Hong Kong. International journal of Project management, 2006; 24(7):587-594.

[2] Fernández-Sánchez, G., \& Rodríguez-López, F. A methodology to identify sustainability indicators in construction project management-Application to infrastructure projects in Spain. Ecological Indicators, 2010; 10(6):11931201.

[3] Bing, L., Akintoye, A., Edwards, P. J., \& Hardcastle, C. The allocation of risk in PPP/PFI construction projects in the UK. International Journal of project management, 2005; 23(1):25-35.

[4] Kikwasi, G. Causes and effects of delays and disruptions in construction projects in Tanzania. In Australasian Journal of Construction Economics and Building-Conference Series 2012; Vol. 1, No. 2:pp. 52-59.

[5] Del Cano, A., \& de la Cruz, M. P. Integrated methodology for project risk management. Journal of construction engineering and management, 2002; 128(6):473-485. 
[6] [6]Crawford, L. Senior management perceptions of project management competence. International journal of project management, 2005; 23(1):7-16.

[7] Harris, F., \& McCaffer, R. Modern construction management. John Wiley \& Sons. 2013

[8] Abdullah, D. N. M. A., \& Wern, G. C. M. An analysis of accidents statistics in Malaysian construction sector. In International Conference on E-business, Management and Economics (2011; Vol. 3:pp. 1-4). Honk Kong: IACSIT Press.

[9] Mahendra, P. A., Pitroda, J. R., \& Bhavsar, J. J. A study of risk management techniques for construction projects in developing countries. International Journal of Innovative Technology and Exploring Engineering, 2013; 3(5):139-142.

[10] Winch, G. M. Managing construction projects. John Wiley \& Sons. 2010

[11] Loosemore, M., Raftery, J., Reilly, C., \& Higgon, D. Risk management in projects. Routledge. 2012

[12] More, M. Risk Management for Construction. 1993

[13] Ritchie, B., \& Brindley, C. Supply chain risk management and performance: a guiding framework for future development. International Journal of Operations \& Production Management, 2007; 27(3):303-322.

[14] Akintoye, A., Beck, M., \& Hardcastle, C. (Eds.). Public-private partnerships: managing risks and opportunities. John Wiley \& Sons. 2008

[15] Pietrosemoli, L., \& Monroy, C. R. The impact of sustainable construction and knowledge management on sustainability goals. A review of the Venezuelan renewable energy sector. Renewable and Sustainable Energy Reviews, 2013; 27:683-691.

[16] Wang, S. Q., Dulaimi, M. F., \& Aguria, M. Y. Risk management framework for construction projects in developing countries. Construction Management and Economics, 2004; 22(3):237-252.

[17] Baldry, D. The evaluation of risk management in public sector capital projects. International Journal of Project Management, 1998; 16(1):35-41.

[18] Mills, A. A systematic approach to risk management for construction. Structural survey, 2001; 19(5):245-252.

[19] Dey, P. K. Managing projects in fast track-A case of public sector organization in India. International Journal of Public Sector Management, 2000; 13(7):588-609.

[20] Shelbourn, M., Bouchlaghem, D., Anumba, C., Carrillo, P., Khalfan, M., \& Glass, J. 2006. Managing knowledge in the context of sustainable construction. Journal of Information Technology in Construction, 2000; 11:57-71.

[21] Belout, A., \& Gauvreau, C. Factors influencing project success: the impact of human resource management. International journal of project management, 2004; 22(1):1-11.

[22] ]Chileshe, N., Berko, P. D., \& Haupt, T. 2010, July. Causes of project cost overruns within the Ghanaian road construction sector. In Proceedings: The 5th Built Environment Conference.

[23] Tang, L., Shen, Q., \& Cheng, E. W. A review of studies on public-private partnership projects in the construction industry. International journal of project management, 2010; 28(7):683-694.

[24] Barlow, J. Innovation and learning in complex offshore construction projects. Research policy, 2000; 29(7-8):973989.

[25] Shen, L. Y., Wu, G. W., \& Ng, C. S. Risk assessment for construction joint ventures in China. Journal of construction engineering and management, 2001; 127(1):76-81.

[26] Karslıŏglu, Y. E., Balcı, B., Bayraktar, O. Y., Kaplan, G. İnşaat projelerinde risk yönetimi ve iş sağlığı ve güvenliği açısından örnek bir risk değerlendirmesi, $5^{\text {nd }}$ International congress on engineering, architecture and design, 2019; 419-430.

[27] Söylemez, H., \& Bayraktar, O. Y. Bor Mineralleri ve Atıkları İle Üretilen Betonarme Yapılarda Yangına Dayanıklılığın Araştırılması, 3rd International Symposium on Innovative Approaches in Scientific Studies, 2019; $4(1) ; 489-492$

[28] Söylemez, H., \& Bayraktar, O. Y. Donatıll Toprak Duvar (Toprakarme) İmalatında Beton Panel Yerine Atık Lastiklerin Kullanılmasının Araştırılması, 3rd International Symposium on Innovative Approaches in Scientific Studies, 2019; 4(1);486-488 
[29] Söylemez, H., Balcı, B., \& Bayraktar, O. Y. Endüstriyel Atıklardan Üretilen Geopolimer Harçların Özellikleri, 5th Internatıonal European Conference On Science, Art \& Culture, 2019; 202-207.

[30] Bayraktar, O. Y., Saglam-Citoglu, G., \& Abo Aisha, A. E. S. The Use of Scrap Tires in the Construction Sector. International Journal of Trend in Research and Development, 2019; 6(1):253-256.

[31] Bayraktar, O. Y., Saglam-Citoglu, G., \& Abo Aisha, A. E. S. Performance Research of Lime Based Mortars. International Journal of Trend in Research and Development, 2019; 6(1):257-259. 